\title{
Commentary: Single-patch, two-patch, caval division... and double-decker?
}

\author{
Harold M. Burkhart, MD, ${ }^{\mathrm{a}}$ Jess L. Thompson, MD, ${ }^{\mathrm{a}}$ and Arshid Mir, MD ${ }^{\mathrm{b}}$
}

\footnotetext{
From the a Division of Cardiovascular and Thoracic Surgery and ${ }^{\mathrm{b}}$ Section of Pediatric Cardiology, University of Oklahoma Health Sciences Center, Oklahoma City, Okla.

Disclosures: Authors have nothing to disclose with regard to commercial support.

Received for publication Feb 10, 2019; accepted for publication Feb 11, 2019; available ahead of print March 12, 2019.

Address for reprints: Harold M. Burkhart, MD, Division of Cardiovascular and Thoracic Surgery, University of Oklahoma Health Sciences Center, PO Box 26901, WP-2230, Oklahoma City, OK 73105 (E-mail: Harold-burkhart@ouhsc.edu).

J Thorac Cardiovasc Surg 2019;157:1978-9

$0022-5223 / \$ 36.00$

Copyright (c) 2019 by The American Association for Thoracic Surgery

https://doi.org/10.1016/j.jtcvs.2019.02.038
}

The repair of partial anomalous pulmonary venous connection (PAPVC) typically involves an intra-atrial baffling of the anomalous pulmonary veins to the left atrium while ensuring an unobstructed systemic venous pathway for the superior vena cava to the right atrium. Techniques involving one patch, two patches, or caval division have been used and largely depend on the location of the aberrant pulmonary veins. ${ }^{1-4}$ Low pulmonary veins draining to the right atrium or the cavoatrial junction can generally be repaired with a single patch. Pulmonary veins draining higher in the superior vena cava are typically better served with caval division, pulmonary vein baffling, and reconstruction of the systemic venous pathway by direct anastomosis of the superior vena cava to the right atrial appendage (Warden procedure). In adults, where there is no growth potential, a short polytetrafluoroethylene interposition graft may be used for superior vena cava reconstruction. These approaches have resulted in low incidences of venous pathway obstruction and arrhythmias. The 2-patch technique, which involves cutting across the cavoatrial junction, has largely been abandoned secondary to concerns of sinus nodal dysfunction and pathway obstruction. ${ }^{5}$

In this issue of the Journal, Hongu and colleagues ${ }^{6}$ report a series of 21 patients in a 20 -year period who underwent their novel double-decker repair technique for PAPVC. The median age at repair was 4.4 years, with a median follow-up of 11 years. The double-decker procedure is essentially a modified 2-patch technique in which a pedicled flap of superior vena cava is used to baffle the pulmonary veins, and then the anterior wall of the superior vena cava is reconstructed with tissue from the right atrial appendage. The potential advantages include the use of autologous tissue for reconstruction and minimizing the right atrial incision. At follow-up, they report no venous pathway obstruction on echocardiography with 4-dimensional flow magnetic resonance imaging performed in 6 patients confirming the open pathways. In addition, none of the patients are reported to have issues with overstated.

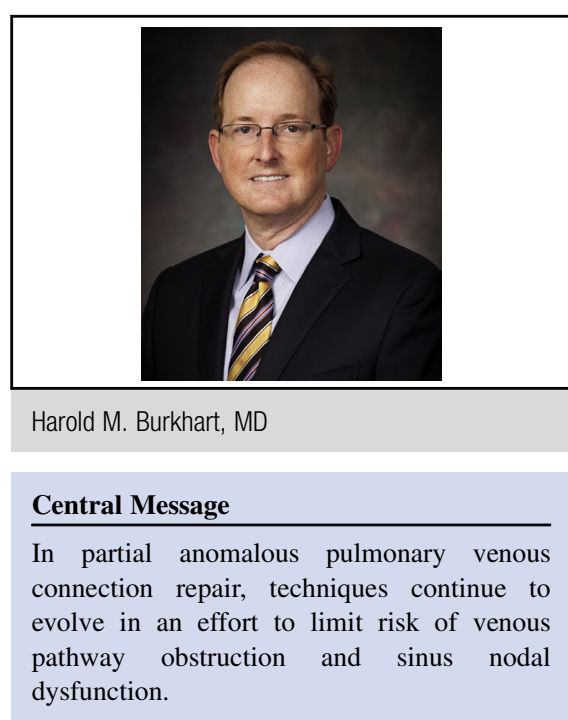

See Article page 1970.

arrhythmias. Overall, this novel approach appears to provide a successful PAPVC repair with minimal intermediate-term issues.

There are a few limitations to the study. The first is that there are relatively few patients, even though the study spans 20 years. Second, the magnetic resonance imaging data are only available for 6 of the 21 patients. Obviously, a larger group of patients with complete follow-up imaging would have made the conclusions more meaningful. The double-decker technique itself has a few concerns. One of the criticisms of PAPVC repair has been the need for manipulation around the conduction system. This procedure seems to be no different, in that it requires surgical manipulation around the sinus node and nodal artery. In addition, sewing baffles within small venae cavae is always a concern with regard to growth and scar formation. Furthermore, some of the patients required patches of autologous pericardium to augment venous pathways in anticipation of appropriate growth of the unpedicled autologous pericardium. Given the aforementioned concerns, the conclusion that late complications are "completely avoided" is likely

In summary, constructing nonobstructive systemic and pulmonary venous pathways while avoiding arrhythmias and sinus nodal dysfunction remains the mainstay of PAPVC repair. The double-decker technique appears 
successfully in addressing these issues at the time of intermediate follow-up. It is possible that this method would be valuable for selected older patients with pulmonary veins returning just above the cavoatrial junction, where additional patch material would not be necessary. As with any new technique, reproducibility and long-term outcomes will need to be assessed.

\section{References}

1. Said SM, Burkhart HM, Schaff HV, Cetta F Jr, Phillips SD, Barnes RD, et al. Single-patch, 2-patch, and caval division techniques for repair of partial anomalous pulmonary venous connections: does it matter? J Thorac Cardiovasc Surg. 2012;143:896-903.
2. Shahriari A, Rodefeld MD, Turrentine MW, Brown JW. Caval division technique for sinus venosus atrial septal defect with partial anomalous pulmonary venous connection. Ann Thorac Surg. 2006;81:224-30.

3. Stewart RD, Bailliard F, Kelle AM, Backer CL, Young L, Mavroudis C. Evolving surgical strategy for sinus venosus atrial septal defect: effect on sinus node function and late venous obstruction. Ann Thorac Surg. 2007;84:1651-5; discussion 1655.

4. Yong MS, Griffiths S, Robertson T, Brink J, d'Udekem Y, Brizard C, et al. Outcomes of the Warden procedure for partial anomalous pulmonary venous drainage in children. Interact Cardiovasc Thorac Surg. 2018;27:422-6.

5. Okonta KE, Agarwal V. Does Warden's procedure reduce sinus node dysfunction after surgery for partial anomalous pulmonary venous connection? Interact Cardiovasc Thorac Surg. 2012;14:839-42.

6. Hongu H, Yamagishi M, Maeda Y, Itatani K, Asada S, Fujita S, et al. Doubledecker repair of partial anomalous pulmonary venous return into the superior vena cava. J Thorac Cardiovasc Surg. 2019;157:1970-7. 